\title{
Power Management and Control of Smart Microgrid Including Renewable Energy and Energy Storage Systems
}

\author{
Khairy Sayed ${ }^{\mathrm{a}}$, Mohamed Mourad ${ }^{\mathrm{b} *}$ \\ ${ }^{a}$ Electrical department, Faculty of Engineering ,University of Sohag, Sohag, Egypt \\ ${ }^{b}$ Electrical department, Faculty of Engineering, University of Assuit, Assuit, Egypt
}

\begin{abstract}
Hybrid AC/DC microgrid is getting common nowadays as a result of increasing DC-compatible loads, renewable energy resources and energy storage systems. The hybrid AC/DC systems with AC and DC loads and energy sources are considered to be the structure of the future smart grids. Strategies of controlling the process of energy conversions and power management are considered from the most critical aspects. The suggested hybrid grid consists of AC loads and wind generator in the AC side and DC loads with energy storage elements and PV generator in the DC side. Bidirectional AC/DC converter is used to link between AC side and DC side to maintain balance and stability of the system under different generation and load conditions. In this paper we present an overview of power management strategy of hybrid AC/DC microgrid with energy storage elements. Control strategy and Maximum power point tracking for the bidirectional converter to maximize power harvesting are also presented. MATLAB/Simulink model for the hybrid microgrid is developed to verify that the proposed model can maintain balance of the system.
\end{abstract}

(C) 2021 Published by Published by Faculty of Engineering - Sohag University. DOI: 10.21608/SEJ.2021.92548.1004

Keywords: Hybrid AC/DC microgrid; Power management; Bidirectioanl converter; MPPT; PV system; Wind Generation; Energy storage.

\section{INTRODUCTION}

The usage of renewable energy increases around the world and recently we can notice that more renewable energy generators are connected in the low voltage AC distribution network as distributed generators (DGs) or $\mathrm{AC}$ microgrids to decrease the carbon footprint due to conventional generators emissions [1]. The study of AC microgrid was the main goal of the previous research topics [2]-[5]. DC microgrids are getting popular due to the higher penetration of DC loads such as computation devices, communication systems, motors with DC drives and LEDs, etc. [6]. However, AC microgrids are still dominant and purely DC microgrids are not expected to emerge exclusively in power grids [7]. AC/DC power conversions are needed to satisfy the integration of DC loads in the normal AC grid, these conversions are not preferred in terms of energy losses, efficiency, and cost. By emerging DC microgrids we can decrease these conversions and as a result the efficiency of system will be improved. Therefor hybrid AC/DC microgrid which consists of both $\mathrm{AC}$ and $\mathrm{DC}$ networks, is proposed to minimize the number of DC/AC or AC/DC conversions and their losses. In hybrid AC/DC microgrid AC and DC compatible units are connected to the AC and DC network accordingly and combine benefits of both AC and DC microgrid [8].

The main benefits of the hybrid AC/DC microgrid are:

- Eliminate the unnecessary AC/DC or DC/AC conversions, which increase energy losses and decrease the efficiency.

- Simplify the system by removing DC rectifiers in AC side, which reduces the cost of electronic products [1015].

Microgrids can be operated in stand-alone mode or grid-connected mode. Due to discontinuity nature of renewable energy resources, other energy sources like diesel generators or energy storage elements have critical rule to ensure continuous power supply to critical loads, to smooth the injected power to grid in grid-connected mode and to enable stand-alone mode of operation and absorb excess energy or discharge energy to meet minimum load requirements [16-22].

\footnotetext{
${ }^{\text {*}}$ Corresponding author: Mohamed.mourad@eng.au.edu.eg
} 
Energy storage elements can be sorted into two categories: access-oriented energy storage and capacityoriented energy storage. Access oriented storage elements such as supercapacitors, flywheels and superconducting magnetic energy storage are used for short time disturbances in microgrid, and they have fast response time by providing the high-frequency component of power. They can absorb or supply the high-power transients with high power density. Capacity-oriented energy storage such as batteries, compressed air energy storage, pumped hydroelectric systems and hydrogen storage are used for long-term energy balancing to recover discontinuity of renewable energy generators and buffer out low-frequency oscillation of output power of the distribution generators and they does not have fast response time [23-29].

The proposed microgrid in this paper has AC and DC sub-grids connected to form the hybrid AC/DC microgrid. The AC sub-grid consists of wind energy system and AC load where the DC sub-grid consists of photovoltaic system and DC load in addition to an energy storage system. For the energy storage system supercapacitors are considered a better choice as they have more charge and discharge cycles during their lifetime, they have long life, better power density and they also can be constructed in modular structure and for residential or industrial applications they provide maintenance free operation, and this can serve as a cost-effective alternative to batteries [30-33].

There are different topologies to connect AC and DC sub-grids are proposed in the previous research. The bidirectional interlinking converter (BIC) is the smart choice to link AC sub-grid to DC sub-grid and form a single hybrid AC/DC microgrid to transfer the power smoothly between the two grids and combine the benefits of both grids. Merging the two sub-grids gives the maximum available power from wind and solar [34-39]. However, the system operation depends on the bidirectional converter, whose failure disrupt the whole system.

Fig. 1 shows schematic diagram of the proposed system, by connecting DC load at DC bus and AC load at AC bus we can reduce number of converters and as a result the efficiency of system will be increased, and the cost will be reduced.

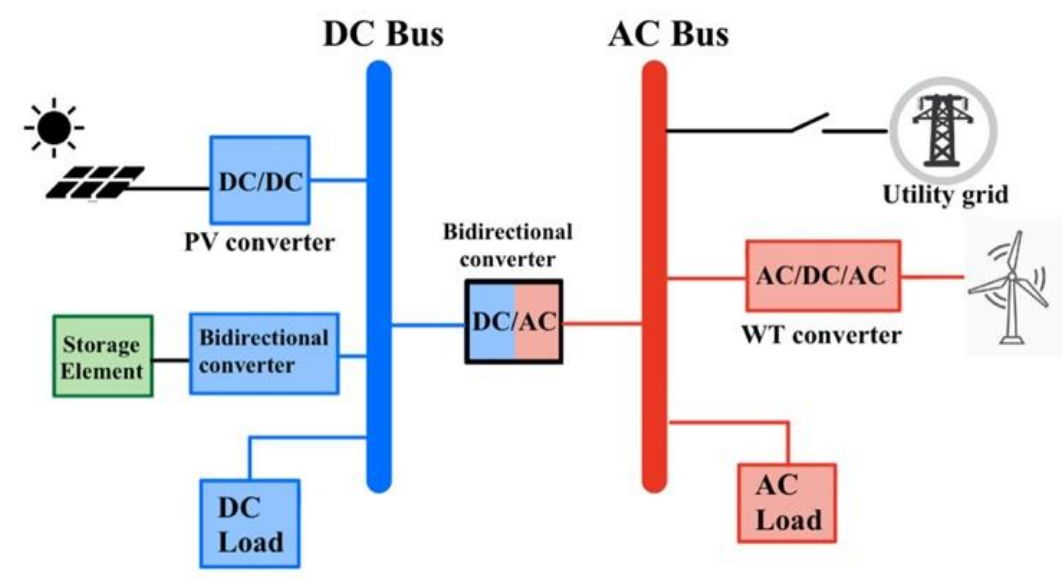

Fig. 1. Hybrid AC/DC microgrid.

There are several energy management strategies for microgrid, the used strategy should be designed to achieve the optimum performance while making sure that the energy sources and storage units work within its predefined limits. The supervisory controller is responsible for controlling the power flow and splitting the power between different energy sources and loads.

The generated power demanded power and the energy level of the storage elements are measured and collected by the supervisory controller, it also controls the power flow from AC bus to DC bus or vice versa through the bidirectional converter. On the other hand, MPPT has to be applied for both PV and Wind energy to maximize harvesting the available power and increase the efficiency of the system.

If the power demand is higher than the power generated from PV and Wind energy, the utility grid will supply the load with the needed power. And if the demanded power is lower than the generated power, the utility grid will absorb the residual power. The system operation is studied in the grid-connected model.

\section{SYSTEM MODELING}

\subsection{AC microgrid modeling}

As shown in Fig. 1 the Wind source is connected to the AC bus and the PV source is connected the DC bus. Fig. 2 shows the Wind turbine of the AC sub-grid. The Permanent magnet synchronous generator (PMSG) is connected to the AC bus through an AC/DC/AC back-to-back converter set. Since the PMSGs are self-excited they are considered appropriate and feasible technology in wind energy generation, and this allows operation at high power factor with high efficiency [15]. 


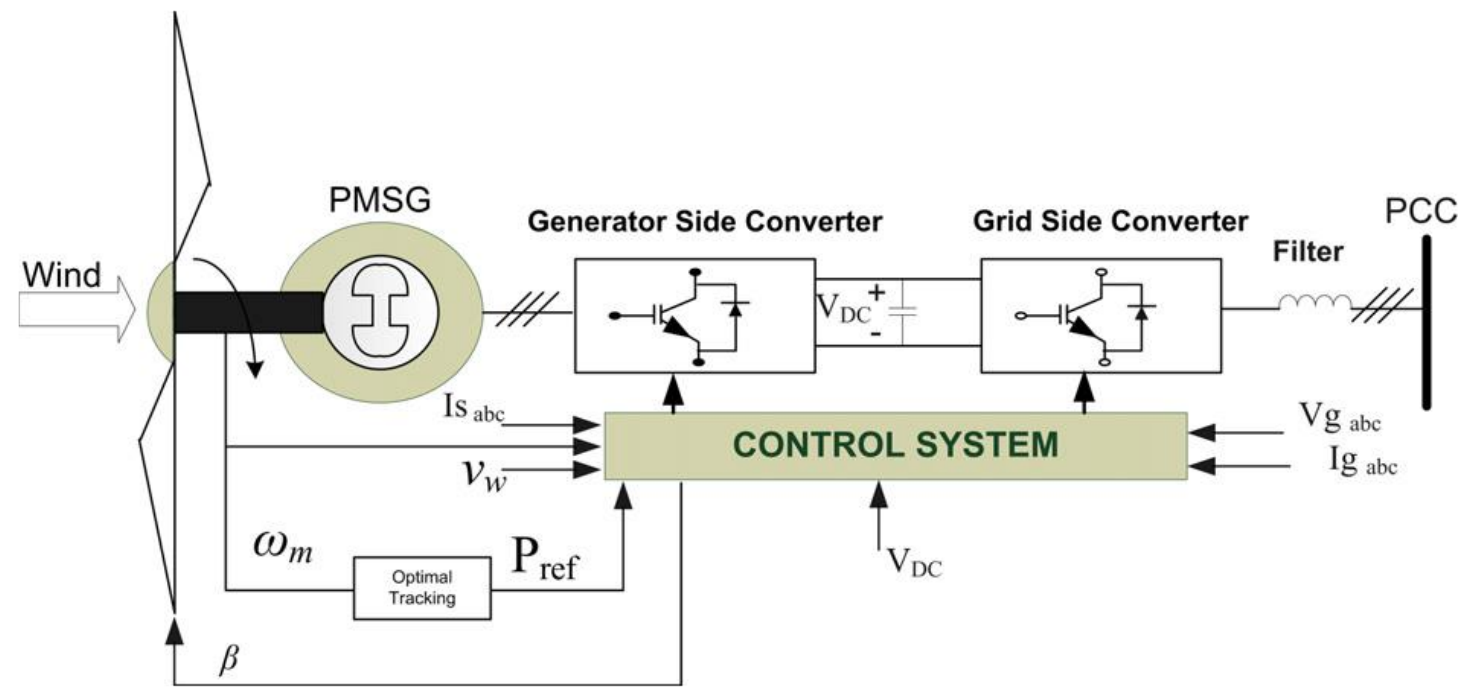

Fig. 2. The Wind Energy Conversion System (WECS).

The Wind Energy Conversion System (WECS) is responsible for converting the kinetic energy of the wind to mechanical energy through the wind turbine rotor blades, then the mechanical power is converted to electrical power through the generator. The WECS is shown in Fig. 2, and it has two main parts:

\subsubsection{Mechanical part: includes the rotor blades with the aerodynamic system and the drive train system (if} existed).

The output power of the Wind Turbine (WT) is given as [16]:

$$
P_{\text {Turbine }}=\frac{1}{2} \rho \pi R^{2} C_{P}(\lambda, \beta) v^{3},
$$

where $\rho$ represents the density of air $(\mathrm{kg} / \mathrm{m} 3), \mathrm{R}$ represents the radius of the blade $(\mathrm{m}), C_{P}$ represents the turbine performance coefficient which is a function of the tip-speed ratio $\lambda$ and the pitch angle of rotor blades $\beta$ (in degrees). $v$ represents the speed of wind $(\mathrm{m} / \mathrm{s})$. Where the tip-speed ratio $\lambda$ is given as:

$$
\lambda=\frac{\omega_{m} R}{v}
$$

where $\omega_{m}$ represents the speed of the wind turbine's rotor $(\mathrm{rad} / \mathrm{sec})$. The output mechanical torque of the wind turbine $T_{m}$ is given as:

$$
\begin{aligned}
& T_{m}=\rho A C_{P}(\lambda, \beta) v^{3} \frac{1}{\omega_{m}} \\
& C_{P}=\frac{1}{2}\left(\frac{116}{\lambda_{i}}-0.4 \beta-5\right) e^{-\left(\frac{21}{\lambda_{i}}\right)} \\
& \frac{1}{\lambda_{i}}=\frac{1}{\lambda+0.08 \beta}-\frac{0.035}{\beta^{3}+1}
\end{aligned}
$$

The optimum tip-speed ratio $\lambda_{\text {opt }}$ represents the tip-speed ratio at maximum values for the power and coefficient of power. So, the maximum value of $C_{P}(\lambda, \beta)$ equals 0.41 is obtained at $\lambda_{\text {opt }}=8.1$ and $\beta=0^{\circ}$. Furthermore, any change in the velocity of wind or the generator speed will result in a change in the tip-speed ratio $\lambda$, which affects the power coefficient and the extracted power.

The power can be maximized if the turbine is kept running at particular speed for various velocities of wind. It is also mandatory to keep the speed of the PMSG at an optimum value of the tip-speed ratio, $\lambda_{\text {opt }}$. Correspondingly, the maximum power is continuously extracted from wind (MPPT) [16], and the system will operate at the peak of power curve as shown in Fig. 3. 


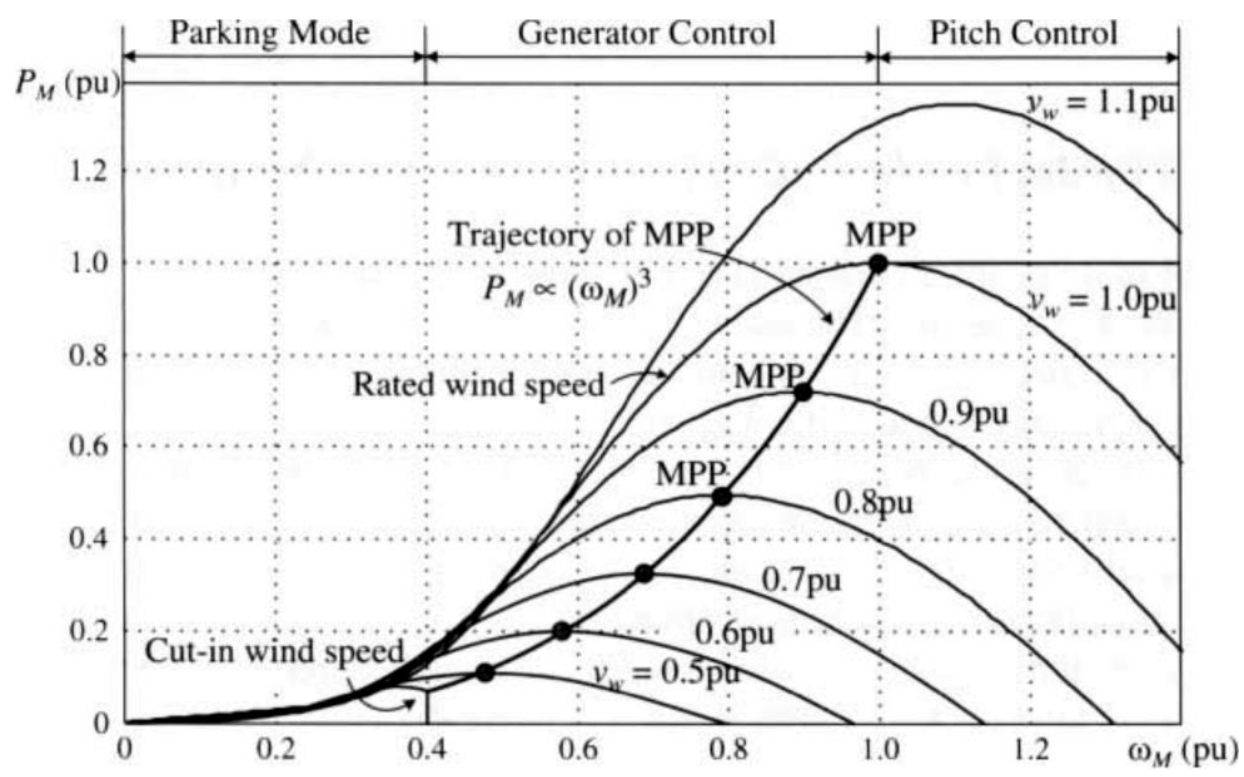

Fig. 3. The power characteristic of the wind turbine.

\subsubsection{Electrical part: consists of the PMSG and back to- back converter set [15].}

The mechanical power is converted to Alternating Current (AC) electrical power by PMSG, this AC power is then converted to Direct Current (DC) power by the converter, finally the inverter is used to transfer the DC power to the grid (AC bus).

Fig. 4 shows the equivalent circuits of PMSG in the direct and quadrature axes. The voltage of the stator in the d-q reference frame, $V_{s d}$ and $V_{s q}$ are given as follows:

$$
\begin{gathered}
V_{s d}=-R_{s} I_{s d}-L_{s} \frac{d}{d t} I_{s d}+L_{s} \omega_{e} I_{s q} \\
V_{s q}=-R_{s} I_{s q}-L_{s} \frac{d}{d t} I_{s q}+L_{s} \omega_{e} I_{s d}+\omega_{e} \emptyset,
\end{gathered}
$$

where $L_{S}$ represents the inductance of the PMSG winding and $R_{S}$ represents the resistance of the PMSG winding, $\emptyset$ is representing the magnet flux, $\omega_{e}$ represents the generator's electrical rotational speed, $I_{s q}$ and $I_{s d}$ are the quadrature and direct components of the machine currents respectively.

The electromagnetic torque $T_{e}$ is given by:

$$
T_{e}=\frac{3}{2} P I_{s q}\left(\left(L_{d}-L_{q}\right) I_{s d}+\emptyset\right),
$$

where $L_{d}, L_{q}$ are the two axes machine inductances and $\mathrm{P}$ is the number of pole pairs. In surface mounted PMSGs, $L_{d}=L_{q}=L_{s}$. Hence, the electromagnetic torque can be rewritten as follows:

$$
T_{e}=\frac{3}{2} P \cdot I_{s q} . \emptyset
$$

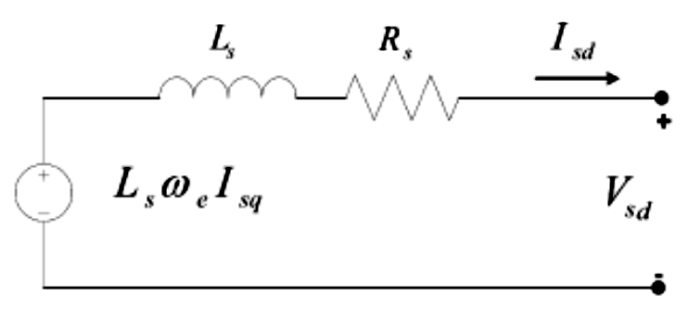

(a)

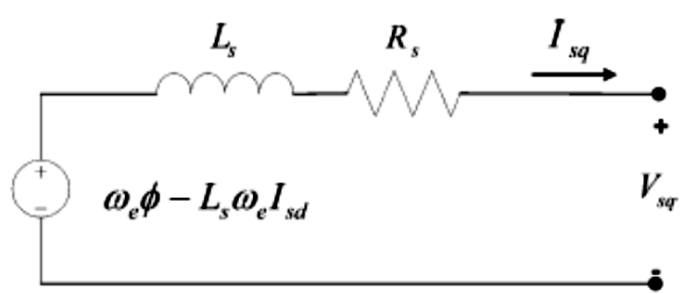

(b)

Fig. 4. Equivalent circuits of PMSG: (a) $d$-axis (b) $q$-axis. 


\subsection{Micro-Grid Modeling}

The DC sub-grid shown in Fig. 1 comprises PV array connected to the DC bus through DC/DC boost converter, which controls the operating point of the array. The practical PV model is shown in Fig. 5.

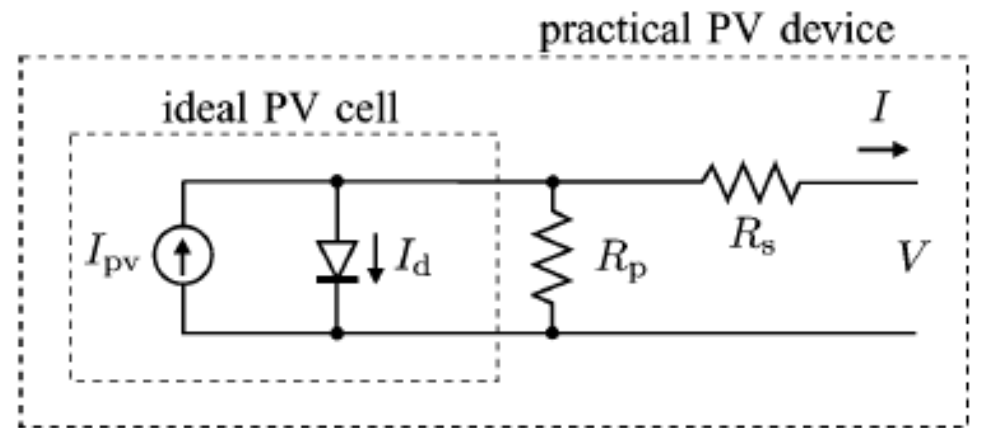

Fig. 5. The equivalent circuit of a practical PV device including the series and parallel resistances.

The generated current by the PV array is calculated based on the following equation [17]

$$
I=I_{P V}-I_{0}\left[\exp \left(\frac{V+R_{s} I}{V_{t} a}\right)-1\right]-\frac{V+R_{s} I}{R_{P}}
$$

Also, $I_{p v}$ and $I_{0}$ are determined as follows:

$$
\begin{gathered}
I_{P V}=\left(I_{P V, n}+K_{I} \Delta T\right) \frac{G}{G_{n}} \\
I_{0}=\frac{I_{s c, n}+K_{I} \Delta T}{\exp \left(\left(V_{o c, n}+K_{V} \Delta T\right) / a V_{t}\right)-1},
\end{gathered}
$$

where $I_{0}$ and $I_{p v}$ are the saturation and photovoltaic (PV) currents of the array respectively. The thermal voltage of PV is given by $V_{t}=N_{s} k T / q$ where $N_{s}$ represents number of cells connected in series. Increasing number of cells connected in parallel will increase the current, while increasing number of cells connected in series will increase the output voltages. $R_{S}$ and $R_{P}$ represent the equivalent series and parallel resistances of the array respectively. $I_{P V, n}$ is the light-generated current at the nominal condition which are usually $25^{\circ} \mathrm{C}$ and $1000 \mathrm{~W} / \mathrm{m}^{2}$, $\Delta T=T-T_{n}$ ( $T$ and $T_{n}$ represent the actual and nominal temperatures [in Kelvin], respectively), $G$ (watts per square meters) represents the irradiation on the photovoltaic surface, $G_{n}$ and $K_{I}$ and $K_{V}$ represent the nominal irradiation, the current and voltage coefficients respectively. The DC bus feeds the DC load by the energy generated by solar subsystem, similar to the AC micro-grid. Fig. 6 shows the $P-V$ and $I-V$ characteristics diagram for the PV module.

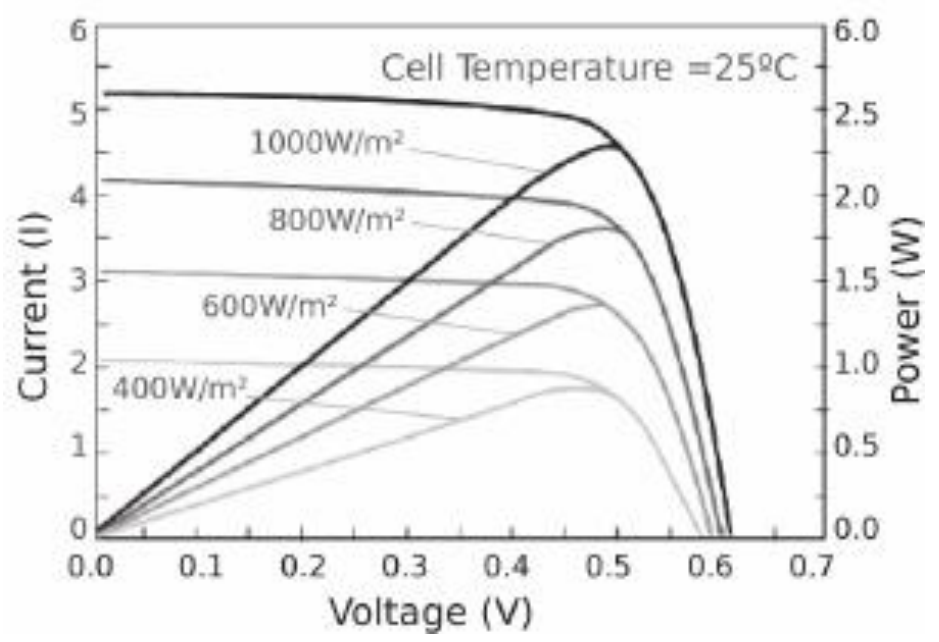

Fig. 6. P-V and I-V charactersitics diagram of the PV module. 


\section{SUPERVISORY POWER MANAGEMENT SYSTEM}

Fig. 7 shows the proposed program, it has a central unit, which is given the data collected from components of microgrid, in order to control the power flow between energy resources.

The input variables to the supervisor controller are generation forecast $\left(P_{W G}^{\mathrm{Max}}, P_{P V}^{\mathrm{Max}}\right)$ and demanded power by loads $\left(P_{L}^{\mathrm{ac}}, P_{L}^{\mathrm{dc}}\right)$. The proposed program determines set-points which controls the amount of power exchanged between the sub-grids $\left(P_{\mathrm{ac} 2 \mathrm{dc}}^{\mathrm{ref}}, P_{\mathrm{dc} 2 \mathrm{ac}}^{\mathrm{ref}}\right)$. The output commands are sent to the bidirectional converter to force the micro-grid components to track the obtained set-points.

Operating modes of the microgrid are divided into two groups. The first group consists of three different modes with no power exchange between the AC and DC sub-grids, the second group consists of six modes with power exchange between the sub-grids, as shown in Fig. 8. When the DC micro-grid injects power to the AC microgrid, the $\mathrm{AC}$ power is obtained from DC/AC inverter. Also, when the AC microgrid injects power to the DC microgrid, the main converter acts as an AC/DC converter.

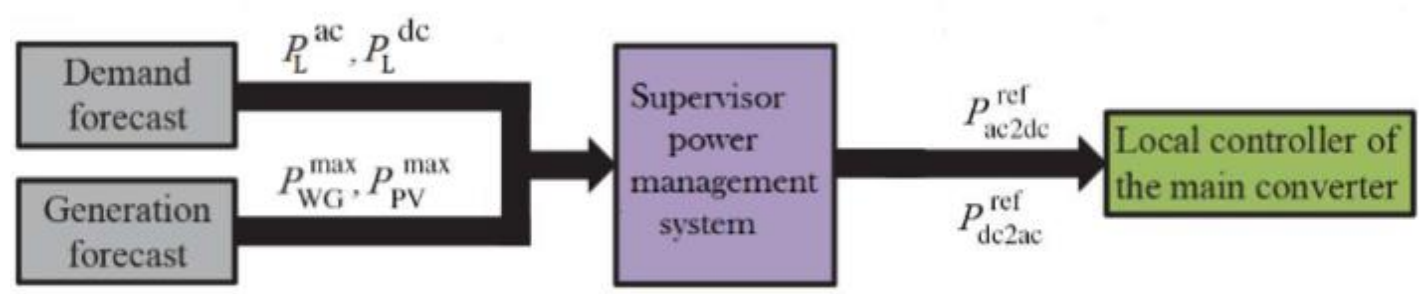

Fig. 7. Power management architecture for hybrid AC/DC micro-grid.

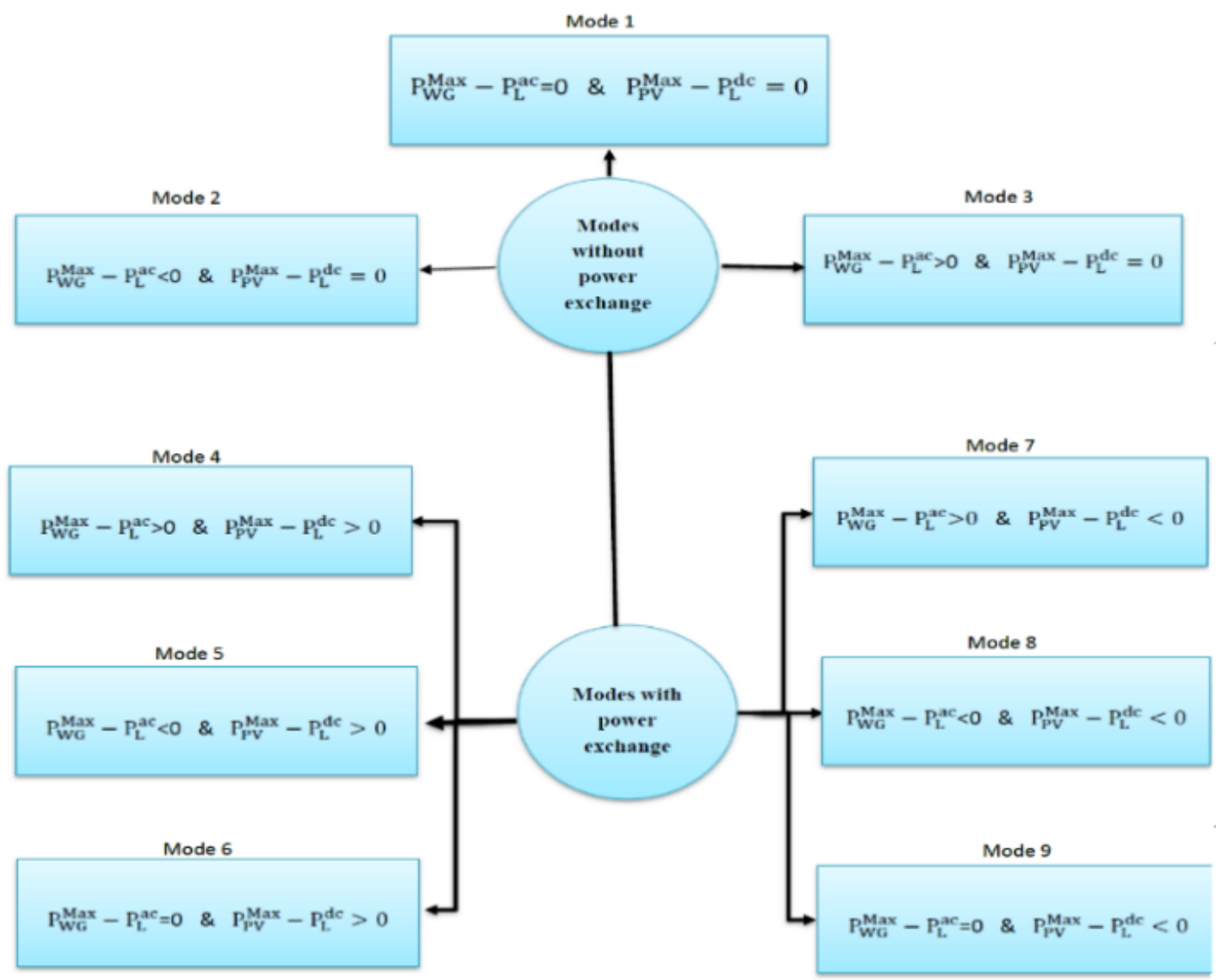

Fig. 8. Different operating modes of the hybrid AC/DC micro-grid.

As shown in Fig. 8, there are two groups with 9 different modes of operation: 


\subsubsection{Modes1,2 and 3:}

In these modes, there is no power exchange between AC and DC sub-grids $\left(P_{\mathrm{ac} 2 \mathrm{dc}}=P_{\mathrm{dc} 2 \mathrm{ac}}=0\right)$. In mode 1 the DC load power $\left(P_{L}^{\mathrm{dc}}\right)$ equals the PV power $\left(P_{P V}^{\mathrm{Max}}\right)$ and AC load power $\left(P_{L}^{\mathrm{ac}}\right)$ equals wind power $\left(P_{W G}^{\mathrm{Max}}\right)$, so there is no power exchange with the grid $\left(P_{\text {grid }}=0\right)$. In mode 2 the DC load power $\left(P_{L}^{d c}\right)$ equals the PV power $\left(P_{\mathrm{PV}}^{\mathrm{Max}}\right)$, while AC load power $\left(P_{L}^{a c}\right)$ is greater than wind power $\left(P_{\mathrm{WG}}^{\mathrm{Max}}\right)$ so the remaining demanded power is absorbed from the grid $\left(P_{\text {grid }}=P_{L}^{\mathrm{ac}}-P_{\mathrm{WG}}^{\mathrm{Max}}\right)$. Mode 3 is the same as mode 2 except that $P_{L}^{a c}$ is lower than $P_{W G}^{M a x}$, so the excess power is supplied to the grid $\left(P_{\text {grid }}=P_{\mathrm{WG}}^{\mathrm{Max}}-P_{L}^{\mathrm{ac}}\right)$.

\subsubsection{Modes 4,5,6,7,8 and 9:}

In these modes, there is power exchange between the AC and DC sub-grids. In modes 4,5 and 6 the power generated from $\mathrm{PV}\left(P_{P V}^{\mathrm{Max}}\right)$ is higher than DC load demand $\left(P_{L}^{d c}\right)$, so the supervisor control will send reference signal to $\mathrm{BIC}$ to transfer the excess power to $\mathrm{AC}$ bus $\left(\mathrm{P}_{\mathrm{DC} 2 \mathrm{AC}}=\mathrm{P}_{\mathrm{PV}}^{\mathrm{Max}}-\mathrm{P}_{\mathrm{L}}^{\mathrm{DC}}\right)$. In these cases, the $\mathrm{AC}$ bus receives power from $\mathrm{BIC}$ and wind generator, so if the $\mathrm{AC}$ load power $\left(\mathrm{P}_{\mathrm{L}}^{\mathrm{AC}}\right)$ is greater than the received power, the grid will supply the remaining demanded power to the load $\left(\mathrm{P}_{\text {grid }}=\mathrm{P}_{\mathrm{L}}^{A C}-\mathrm{P}_{\mathrm{WG}}^{\mathrm{Max}}-\mathrm{P}_{\mathrm{DC} 2 A C}\right)$. On the other hand, if the $\mathrm{AC}$ load power $\left(\mathrm{P}_{\mathrm{L}}^{\mathrm{AC}}\right)$ is lower than the received power, the grid will absorb the excess power $\left(\mathrm{P}_{\text {grid }}=\mathrm{P}_{\mathrm{WG}}^{\mathrm{Max}}-\right.$ $\left.\mathrm{P}_{\mathrm{L}}^{\mathrm{AC}}+\mathrm{P}_{\mathrm{DC} 2 \mathrm{AC}}\right)$. On the contrary, in modes 7,8 and 9 the power generated from $\mathrm{PV}\left(P_{P V}^{\mathrm{Max}}\right)$ is lower than DC load demand $\left(P_{L}^{\mathrm{dc}}\right)$, so the power will be transferred from AC bus to DC bus $\left(\mathrm{P}_{\mathrm{AC} 2 \mathrm{DC}}=\mathrm{P}_{\mathrm{PV}}^{\mathrm{Max}}-\mathrm{P}_{\mathrm{L}}^{\mathrm{DC}}\right)$.

If the wind power $\left(P_{W G}^{\mathrm{Max}}\right)$ is larger than $\left(\mathrm{P}_{\mathrm{L}}^{\mathrm{AC}}\right)$ and $\left(\mathrm{P}_{\mathrm{AC} 2 \mathrm{DC}}\right)$ then the grid will absorb the excess power $\left(\mathrm{P}_{\text {grid }}=\mathrm{P}_{W G}^{\mathrm{Max}}-\mathrm{P}_{\mathrm{L}}^{\mathrm{AC}}-\mathrm{P}_{\mathrm{AC} 2 \mathrm{DC}}\right)$. But if $\left(P_{W G}^{M a x}\right)$ is lower than $\left(\mathrm{P}_{\mathrm{L}}^{\mathrm{AC}}\right)$ and $\left(\mathrm{P}_{\mathrm{AC} 2 \mathrm{DC}}\right)$ then the grid will supply the remaining demanded power $\left(\mathrm{P}_{\text {grid }}=\mathrm{P}_{\mathrm{L}}^{\mathrm{AC}}+\mathrm{P}_{\mathrm{AC} 2 \mathrm{DC}}-\mathrm{P}_{\mathrm{WG}}^{\mathrm{Max}}\right)$. So, the bidirectional converter (BIC) receives the reference powers determined by the supervisor control and controls the power flow between AC and DC buses.

\section{COORDINATION CONTROL OF THE CONVERTERS}

There are four types of converters in the proposed hybrid grid. When the microgrid operates in grid-connected mode these converters have to be tied with the utility grid to supply an uninterrupted power to variable DC and $\mathrm{AC}$ loads under different circumstances of solar irradiation, temperature and wind speed. The control techniques for the converters are presented in this section.

\subsection{PV control}

In the grid-connected mode, the main objective of the boost converter is to track the maximum power point (MPP) of the PV array by regulating its terminal voltage. The task of MPPT algorithm is to determine $V_{\text {ref }}\left(V_{\mathrm{mp}}\right)$. Another control loop using Pulse Width Modulation (PWM) regulates the input voltage of the converter using proportional and integral (PI) controller, which aims to minimize the error between $V_{\text {ref }}$ and the measured voltage by adjusting the duty cycle. The PI control loop operates at faster rate, provides fast response, and increases the overall system stability.

Simple analog MPPT circuit can be developed by using two voltage approximation lines (VALs) that approximate the maximum power point (MPP) locus. Fast and low-cost analog MPPT method for low power PV systems is proposed from [18].

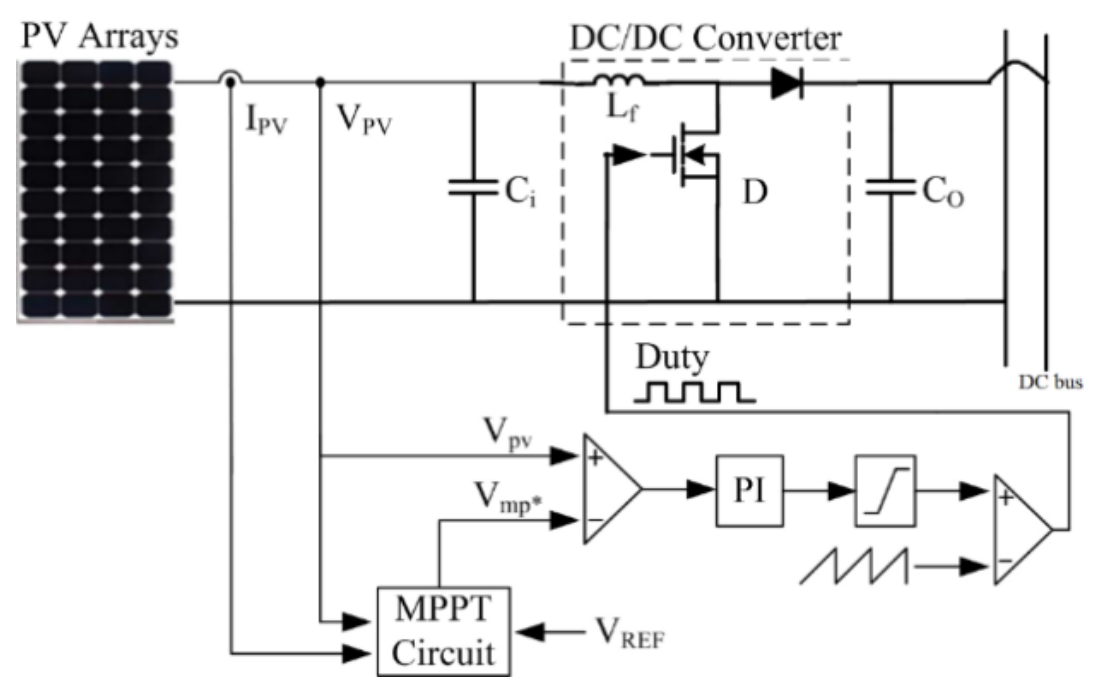

Fig. 9. The block diagram of the boost converter with MPPT. 


\section{2. wind generation control}

As shown in Fig. 2, PMSG of variable speed wind turbines is connected to the utility grid via a back-to-back set of converters. The first converter is known as the generator side converter, and it is connected to the stator windings of the PMSG. While the other one is known as grid side converter, and it is connected to the grid at the Point of Common Coupling (PCC) via an AC filter. The DC terminals of the two converters are connected together through shunt DC capacitor. The power scheme of each converter simply contains a three legs voltage source inverter. However, from control perspective there are different control schemes based on the control functions can be applied to the inverter switches.

\subsection{Control of the generator side converter}

The generator side converter control is mainly used to control the wind turbine shaft speed in order to maximize the output power. In a variable speed wind energy conversion system, the maximum power at different wind speeds depends on the power coefficient, $C_{p}$. Unfortunately, for wind turbines, $C_{p}$ is not constant. The parameters affecting the coefficient $C_{p}$ are the tip speed ratio $\lambda$ and the pitch angle $\beta$ [15]. To obtain the maximum power production $\left(P_{\max }\right)$ from the wind turbine, the turbine should operate at maximum value of the coefficient $C_{p}$. Hence, it is necessary to keep the generator rotor speed $\omega_{m}$ at an optimum value of the tip-speed ratio $\left(\lambda_{\text {opt }}\right)$. According to the power curve shown in Fig. 3, If the wind speed varies, the rotor speed should be adjusted to follow the change of the wind speed. The generator speed control is typically accomplished through the generator side converter. Hence, the control of the generator-side converter allows the generator to tune the rotational speed according to the variation of wind speed. The generator rotational speed is governed by the electromagnetic torque. From

(), the electromagnetic torque may be controlled directly by $q$-axis current component $I_{s q}$, hence the speed can be controlled by changing the q-axis current component. The d-axis current component $I_{s d}$ is set to zero to minimize the current flow for a given torque, which minimizes the resistive losses. The stator voltage components $V_{s d}$ and $V_{s q}$ are synthesized by the generator side converter, both of them can be employed to govern the generator current components $I_{s d}$ and $I_{s q}$ as seen in () and (). The controller requires feedback from the PMSG stator current components $I_{s d}$ and $I_{s q}$. The error between measured and reference components is the input to PI controller. Then, compensation terms shown in (6) and (7) are considered to ensure stability and decoupling of active and reactive power control as shown in Fig. 10. Then the output voltage will be the input to space vector modulation (SVM) to produce switching signal to drive the generator side converter [15].

\subsection{Control of the grid side converter}

The main objective of the grid-side converter control is to regulate the DC bus voltage while controlling the active power and reactive power injected into the grid [19]. The control strategy of the grid side converter contains two cascaded loops as shown in Fig. 11. The inner loop controls the grid currents, and the outer loop controls the DC-link voltage and the reactive power. In this control strategy, the currents are represented in the $d-q$ synchronous rotating reference frame and controlled with standard PI controllers. This control transforms the grid voltages and currents from the abc to their equivalents in the d-q reference frame. It could be seen from Fig. 11 that the outer loop control the DC voltage by taking the DC voltage reference of $1150 \mathrm{~V}$ [20], then the error signal produces Igd reference, which is used by the inner current control loop to control the active power. The second channel controls the reactive power by producing Igq reference and send it to the inner current control loop. The reactive power is set to zero. A phase locked loop (PLL) is required to track the grid voltage vector and to generate the grid voltage angle $\theta_{g}$.

\subsection{Bidirectional Converter Control}

The objective of BIC is to control the power flow between DC and AC buses with respect to the power demanded by the loads and the power generated. It is also responsible for regulating the DC bus voltage. Power control strategies are normally used to control the output power using prespecified reference values for active power and reactive power compensation as shown in Fig. 12. 


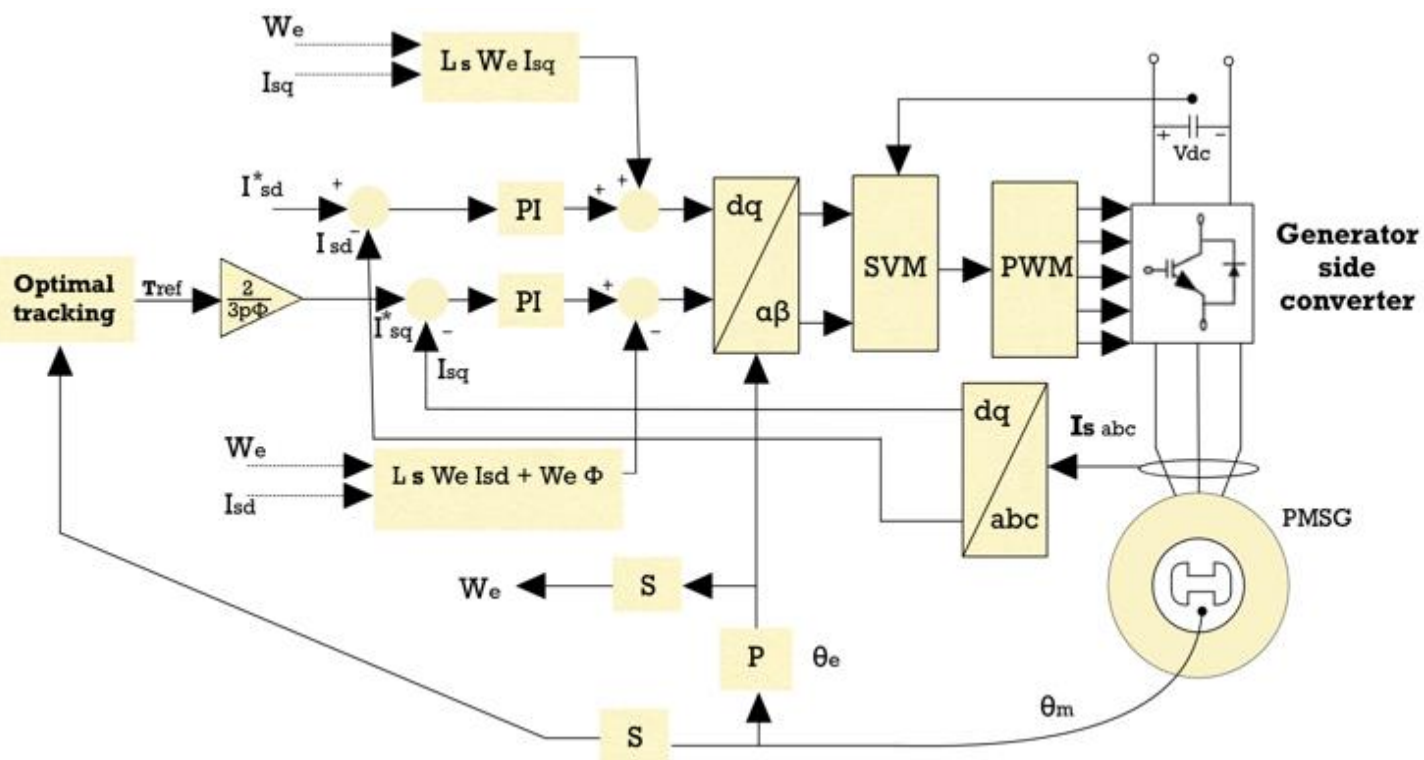

Fig. 10. Block diagram of generator side converter.

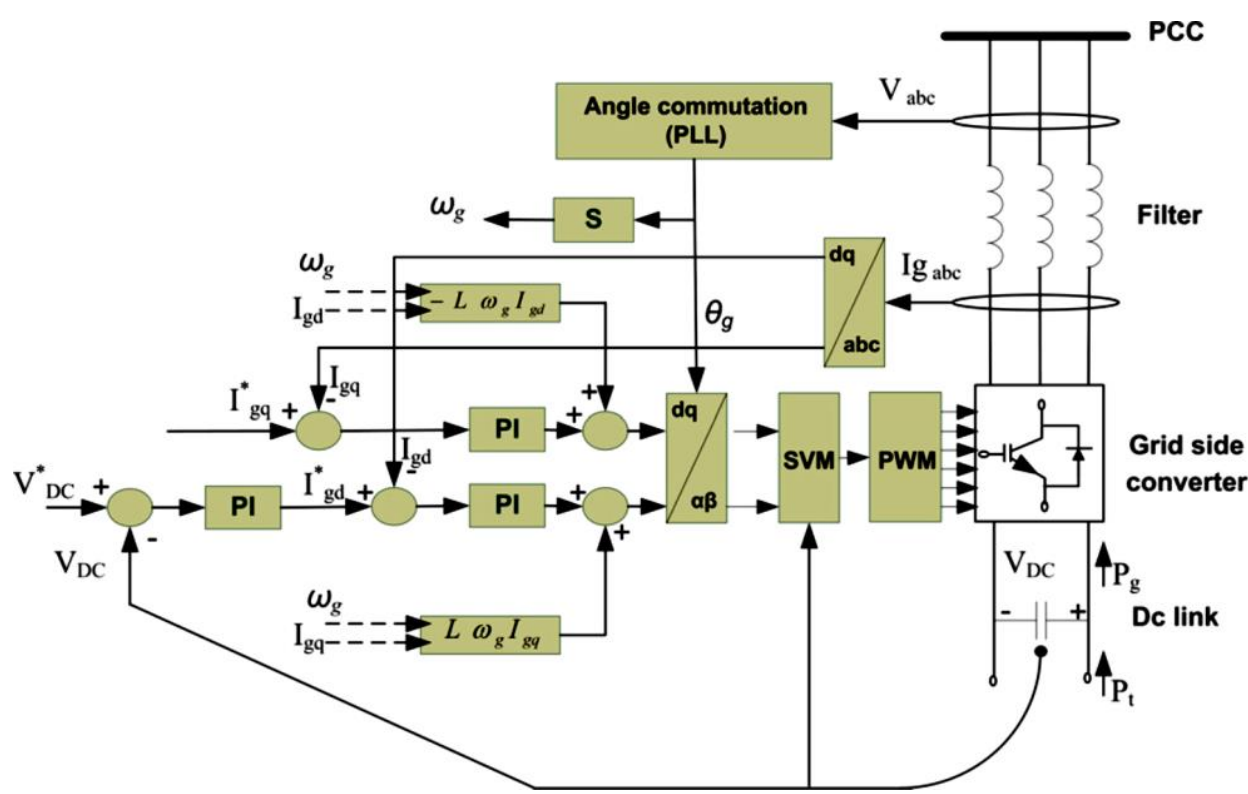

Fig. 11. Block diagram of grid side converter.

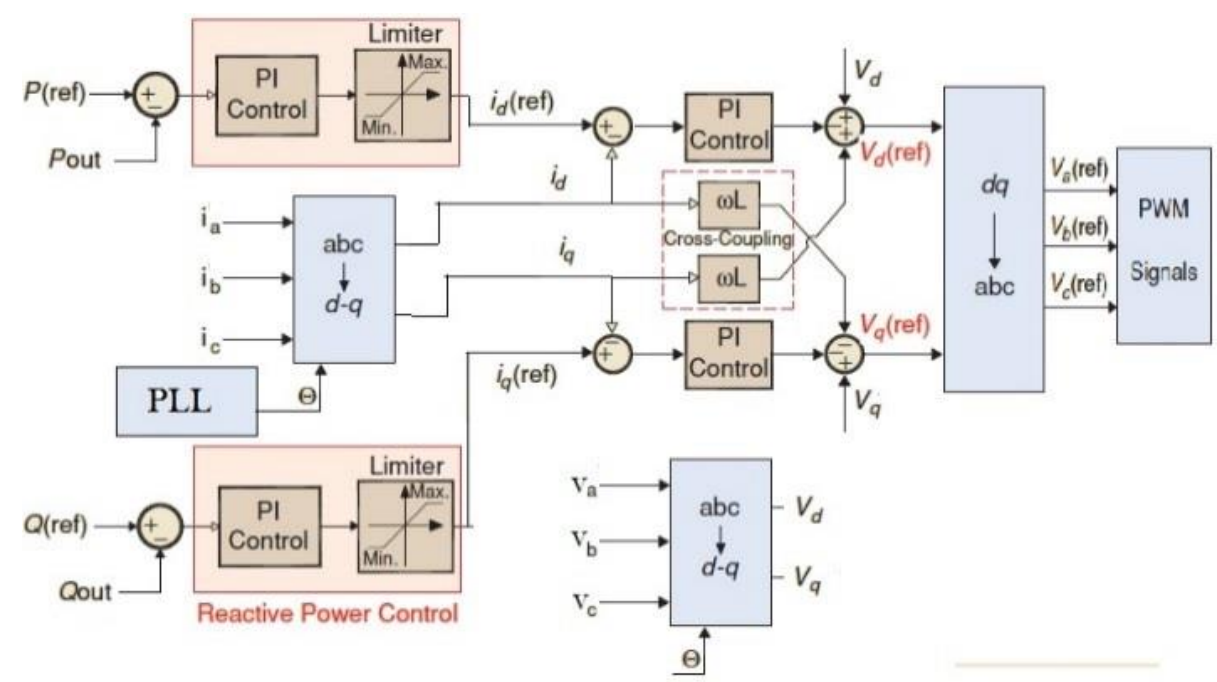

Fig. 12. Active and reactive powers control of BIC. 
So, the control scheme of BIC depends on the set-points $\left(P_{\text {ref }}\right.$ and $\left.Q_{\text {ref }}\right)$ for active and reactive powers control. Where $P_{\text {out }}$ and $Q_{\text {out }}$ are the active and reactive power outputs calculated from the measured output voltages and currents of the unit. $P_{\text {ref }}$ and $Q_{\text {ref }}$ values can be set by a supervisory power management system to optimize the output active and reactive powers. The DC bus voltage controlled and regulated at $500 \mathrm{~V}$.

\section{SIMULATION RESULTS}

The operation of hybrid grid under various sources and loads conditions are simulated to verify validity of the proposed supervisor control algorithms. The parameters used in simulations are given in Tables 1 and 2. All the simulations are performed using MATLAB/Simulink package.

TABLE 1. WIND GENERATION DATA

\begin{tabular}{cccc}
\hline PMSG DATA & \multicolumn{3}{c}{ WIND TURBINE DATA } \\
\hline Rated Power $(\mathrm{MVA})$ & 1.5 & Wind Speed $(\mathrm{m} / \mathrm{s})$ & $7-12$ \\
Rated Voltage $(\mathrm{V})$ & 575 & Blade Radius $(\mathrm{m})$ & 33 \\
Stator Resistance $(\Omega)$ & 0.006 & $\begin{array}{c}\text { Grid Side Coupling } \\
\text { Impedance R }(\Omega)\end{array}$ & 0.03 \\
Stator Inductances & $0.3 e^{-3}$ & Grid Side Coupling & 0.3 \\
$L_{d}, L_{q}(\mathrm{H})$ & 48 & Impedance L $(\mathrm{H})$ & 1150 \\
Number of Poles & 1.48 & Dc Link Voltage $(\mathrm{V})$ & \\
Flux Linkage & 125 & & \\
Rated Speed (rpm) & &
\end{tabular}

TABLE 2. PV MODULE DATA

\begin{tabular}{cc}
\hline Parameter & Value \\
\hline STC Power Rating Pmp $(\mathrm{W})$ & 305 \\
Open Circuit Voltage $V_{o c}(\mathrm{~V})$ & 64.2 \\
Short Circuit Current $I_{s c}(\mathrm{~A})$ & 596 \\
Voltage at Maximum Power $V_{m p}(\mathrm{~V})$ & 54.7 \\
Current at Maximum Power $I_{m p}(\mathrm{~A})$ & 5.58 \\
Temperature Coefficient of $I_{s c}$ & $0.057 \% /{ }^{\circ} \mathrm{C}$ \\
Temperature Coefficient of $V_{o c}$ & $-027 \% /{ }^{\circ} \mathrm{C}$ \\
$N_{s}$ & 5 \\
$N_{p}$ & 66 \\
STC Power Rating Pmax $(\mathrm{kw})$ & 100.7 \\
\hline
\end{tabular}

\subsection{Results of weather change on renewable energy}

In the simulations, the main converter is assumed to be ideal. The weather conditions are changed to test the MPPT algorisms for PV system and wind energy system. So, the Weather conditions and the output PV power and voltage are shown in Fig. 13. The optimal terminal voltage and the output power are determined using the MPPT algorithm based on the corresponding temperature and solar irradiation. The output results are shown in Table 3.

TABLE 3. PV POWER AND VOLTAGE WITH DIFFERENT WEATHER CONDITRIONS

\begin{tabular}{lllll}
\hline & $\begin{array}{l}\text { Irradiance } \\
\left(\mathrm{W} / \mathrm{m}^{2}\right)\end{array}$ & $\begin{array}{l}\text { Temperature } \\
\left({ }^{\circ} \mathrm{c}\right)\end{array}$ & $\begin{array}{l}\text { PV power } \\
(\mathrm{kW})\end{array}$ & $\begin{array}{l}\text { PV voltage } \\
(\mathrm{V})\end{array}$ \\
\hline Case 1 & 1000 & 25 & 100.7 & 273.5 \\
Case 2 & 250 & 25 & 24.4 & 265.1 \\
Case 3 & 1000 & 25 & 100.7 & 273.5 \\
Case 4 & 1000 & 50 & 92.9 & 250.2
\end{tabular}

On the other hand, Fig. 14 shows the maximum power production $\left(\mathrm{P}_{\max }\right)$ from the wind turbine with changing the wind speed from $9 \mathrm{~m} / \mathrm{s}$ to $12 \mathrm{~m} / \mathrm{s}$. The maximum output power generated from wind generation changes from $500 \mathrm{kw}$ to $1318 \mathrm{kw}$. 

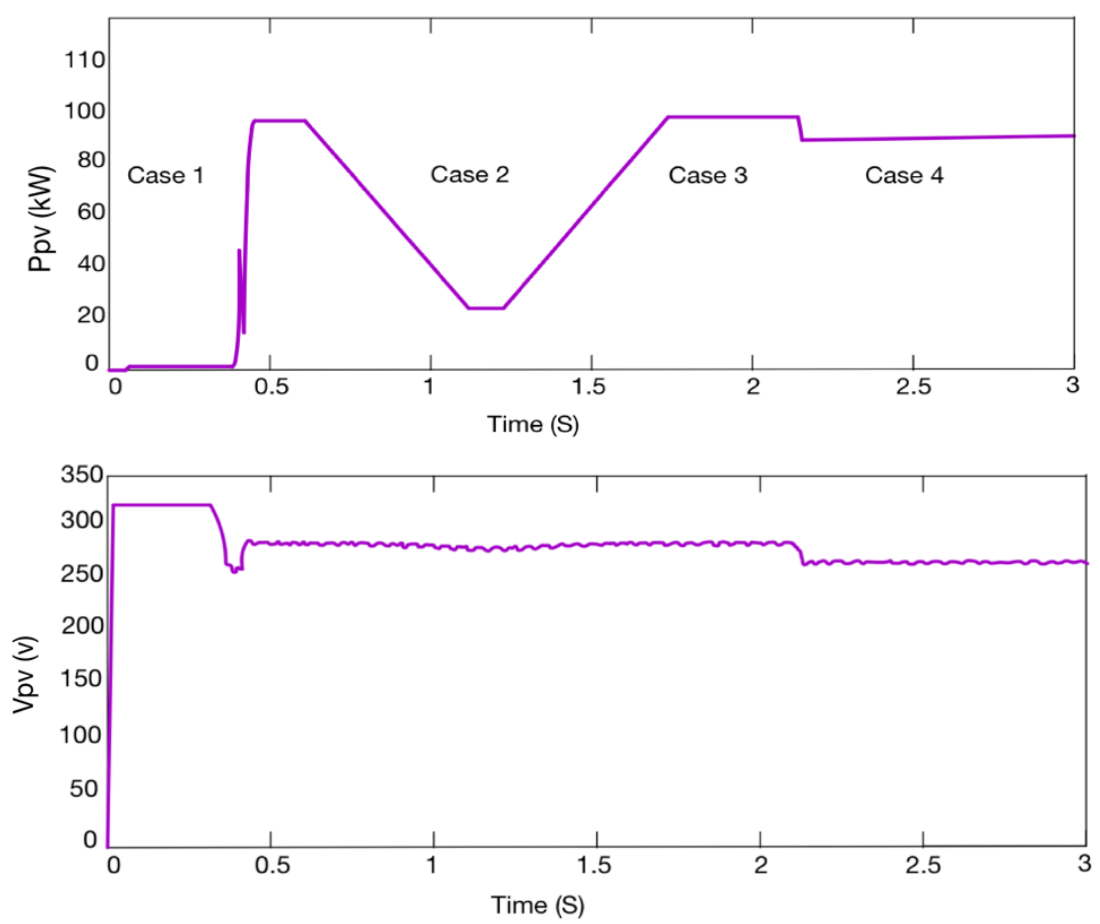

Fig. 13. PV output power and voltage under variable Weather conditions.

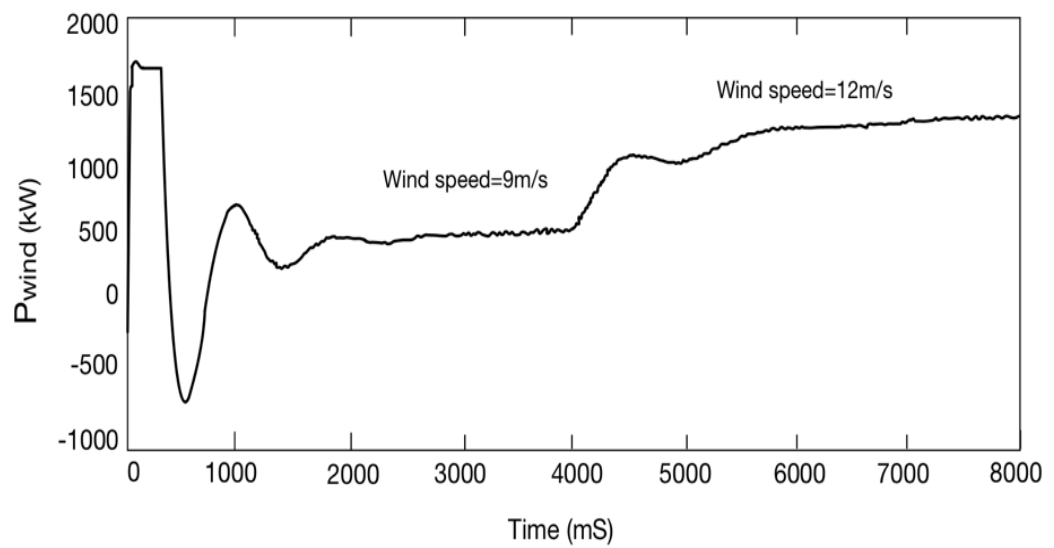

Fig. 14. Wind output power under different wind speed.

\subsection{Supervisor control results}

The demanded power and maximum available power of the proposed microgrid are tested at the following weather conditions: irradiance $1000 \mathrm{~W} / \mathrm{m}^{2}$, temperature $50^{\circ} \mathrm{C}$ and wind speed of $12 \mathrm{~m} / \mathrm{s}$.

\subsubsection{Case A:}

In this mode the generated DC power $P_{P V}^{\mathrm{Max}}$ is higher than the DC load power $P_{L}^{D C}$ so the excess power will be transferred from DC bus to AC bus as shown in Fig. 15. The results are shown in Table 4. The power is transferred from the inverter using the reference power signal from supervisor control. On the other hand, the difference between $P_{W G}^{\mathrm{Max}}$ and $P_{L}^{A C}$ equals $360.04 \mathrm{~kW}$. So, the resultant power that will be delivered to the grid equals $428.74 \mathrm{~kW}$. 

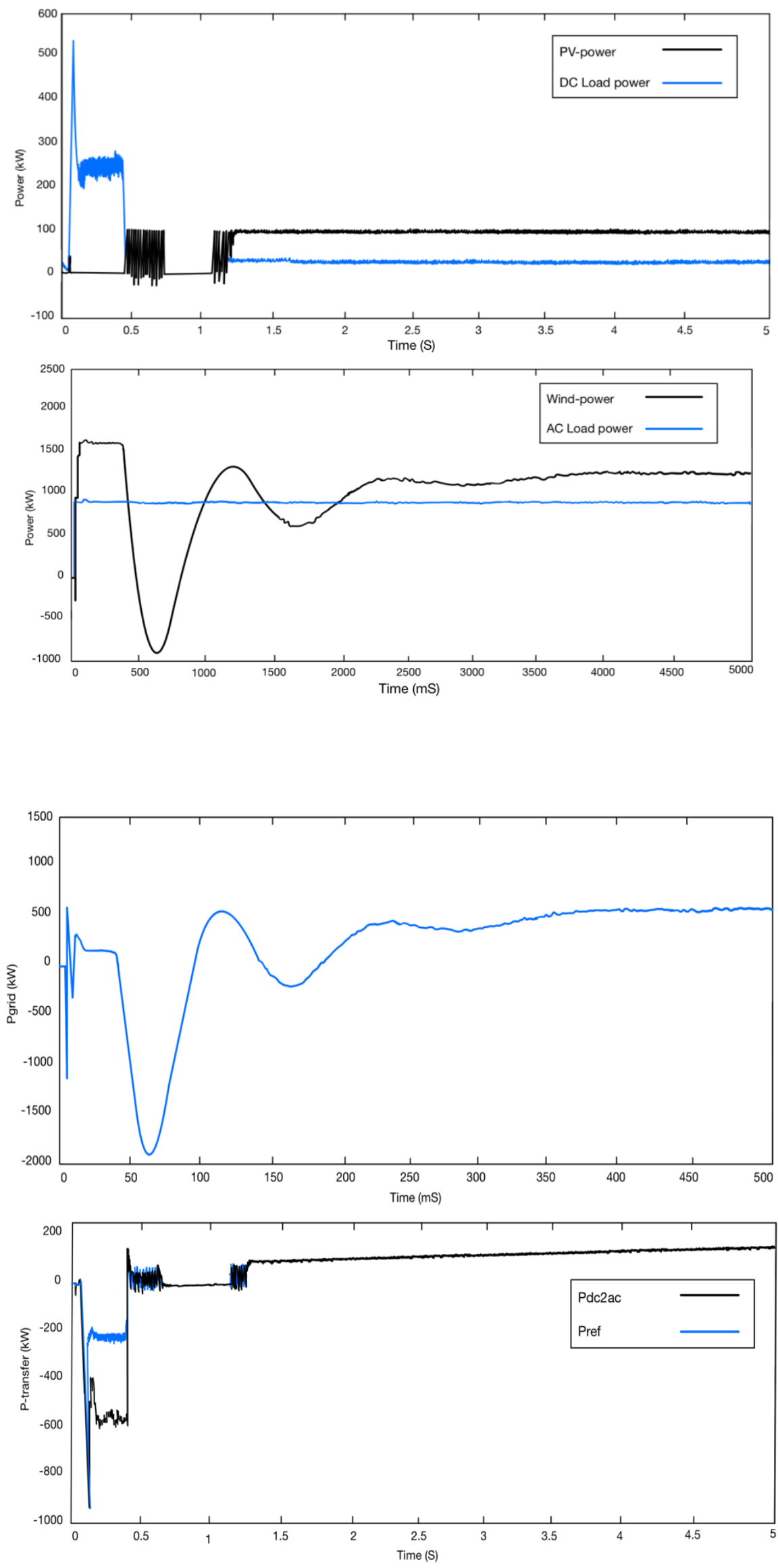

Fig. 15. case A: DC bus power, AC bus power, grid power and PDC2AC with $P_{\text {ref }}$. 
TABLE 4. THE RESULTS OF CASE A

\begin{tabular}{cl}
$\mathrm{P}_{\mathrm{PV}}^{\mathrm{Max}}$ & $92.8(\mathrm{~kW})$ \\
$\mathrm{P}_{\mathrm{L}}^{\mathrm{DC}}$ & $24.1(\mathrm{~kW})$ \\
$\mathrm{P}_{\mathrm{WG}}^{\mathrm{Max}}$ & $1312.98(\mathrm{~kW})$ \\
$\mathrm{P}_{\mathrm{L}}^{\mathrm{AC}}$ & $952.94(\mathrm{~kW})$ \\
$\mathrm{P}_{\mathrm{dc} 2 \mathrm{ac}}$ & $68.7(\mathrm{~kW})$ \\
$\mathrm{P}_{\mathrm{ac} 2 \mathrm{dc}}$ & $0(\mathrm{~kW})$ \\
$\mathrm{P}_{\text {ref }}$ & $68.77(\mathrm{~kW})$ \\
$\mathrm{P}_{\text {grid }}$ & $428.74(\mathrm{~kW})$ \\
\hline
\end{tabular}

\subsubsection{Case B:}

If the $\mathrm{AC}$ load power $P_{L}^{\mathrm{AC}}$ is greater than the wind power $P_{W G}^{\mathrm{Max}}$, the grid will supply the remaining demanded power and the grid power will be denoted with a negative sign as shown in Table 5. On the other hand, if the DC load $P_{L}^{\mathrm{DC}}$ is increased to be larger than the PV power $P_{P V}^{\mathrm{Max}}$, the power will be transferred from AC bus to DC bus to cover this difference as shown in Fig. 16 after the third second.
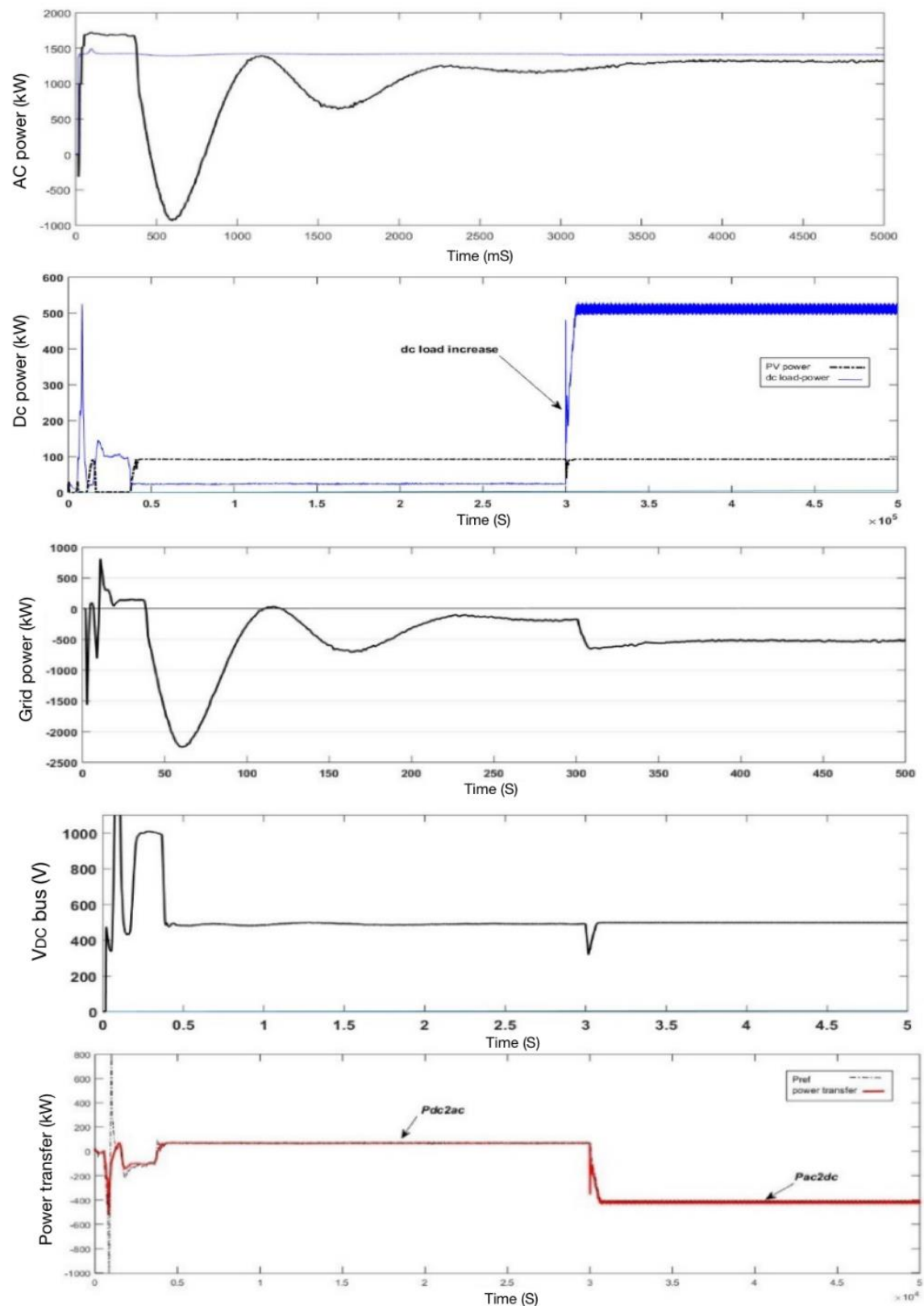

Fig. 16. Case B: DC bus power, AC bus power, grid power, DC bus voltage, Pac2dc and Pdc2dc with sudden change in dc load. 


\begin{tabular}{lll} 
& TABLE 5. THE RESUlTS OF CASE B \\
\hline Time $(\mathrm{sec})$ & $0-3$ & $3-5$ \\
$\mathrm{P}_{\mathrm{PV}}^{\mathrm{Max}}(\mathrm{kW})$ & 92.8 & 92.8 \\
$\mathrm{P}_{\mathrm{L}}^{\mathrm{DC}}(\mathrm{kW})$ & 24.1 & 515.5 \\
$\mathrm{P}_{\mathrm{WG}}^{\mathrm{Max}}(\mathrm{kW})$ & 1319.5 & 1319.5 \\
$\mathrm{P}_{\mathrm{L}}^{\mathrm{AC}}(\mathrm{kW})$ & 1410 & 1410 \\
$\mathrm{P}_{\mathrm{dc}} \mathrm{ac}(\mathrm{kW})$ & 68.7 & 0 \\
$\mathrm{P}_{\mathrm{ac} 2 \mathrm{dc}}(\mathrm{kW})$ & 0 & 422.67 \\
$\mathrm{P}_{\text {ref }}(\mathrm{kW})$ & 68.77 & 422.67 \\
$\mathrm{P}_{\text {grid }}(\mathrm{kW})$ & -180 & -520.88 \\
Vdc bus $(\mathrm{V})$ & 492.5 & 497.86 \\
\hline
\end{tabular}

\section{CONCLUSION}

In this paper, a supervisory control for a grid connected hybrid AC/DC microgrid is proposed to control power flow between $\mathrm{AC}$ and DC buses. Connecting the $\mathrm{DC}$ and $\mathrm{AC}$ loads to $\mathrm{DC}$ and $\mathrm{AC}$ buses respectively reduces number of converters in the hybrid microgrid and as a result reduces losses and harmonics in the proposed system and this is the main idea of AC-DC microgrid. MPPT algorithms are applied to PV and wind generation systems to extract the maximum available power to achieve maximum efficiency. Adjusting the control scheme of converters in the proposed system and testing it under different weather conditions. An energy management strategy of a hybrid microgrid with energy storage systems was studied. The role of energy storage systems within a microgrid to improve the stability, reliability, resiliency, and power quality as well as facilitating the energy management within hybrid microgrid is also addressed. Under the proposed scheme, the distributed ESSs in both ac and dc sides are then automatically coordinated and controlled to balance transient power disturbances, which can effectively improve stability and controllability of the proposed system The supervisory controller is tested with different operation modes.

\section{References}

[1] X. Liu, P. Wang, and P. C. Loh, "A hybrid AC/DC microgrid and its coordination control," IEEE Trans. Smart Grid, vol. 2, no. 2, pp. 278-286, 2011.

[2] J. Rocabert, A. Luna, F. Blaabjerg, and I. Paper, "Control of Power Converters in AC Microgrids.pdf," IEEE Trans. Power Electron., vol. 27, no. 11, pp. 4734-4749, 2012.

[3] I. U. Nutkani, F. Blaabjerg, and P. C. Loh, "Power flow control of intertied ac microgrids," IET Power Electron., vol. 6, no. 7, pp. 1329-1338, 2013.

[4] V. Nasirian, Q. Shafiee, J. M. Guerrero, F. L. Lewis, and A. Davoudi, "Droop-Free Distributed Control for AC Microgrids," IEEE Trans. Power Electron., vol. 31, no. 2, pp. 1600-1617, 2016.

[5] J. G. de Matos, L. A. de S. Ribeiro, and E. de Carvalho Gomes, "Power control in AC autonomous and isolated microgrids with renewable energy sources and energy storage systems," IECON 2013 - 39th Annu. Conf. IEEE Ind. Electron. Soc., pp. 1827-1832, 2013.

[6] X. Jianfang, W. Peng, L. Setyawan, J. Chi, and C. F. Hoong, "Energy Management System for Control of Hybrid AC / DC Microgrids," pp. 778-783, 2015.

[7] N. Eghtedarpour and E. Farjah, "Power Control and Management in a Hybrid AC / DC Microgrid," vol. 5, no. 3, pp. 1494-1505, 2014.

[8] A. A. A. Radwan and Y. A. R. I. Mohamed, "Networked Control and Power Management of AC/DC Hybrid Microgrids," IEEE Syst. J., pp. 1-12, 2014.

[9] M. Hosseinzadeh, S. Member, F. R. Salmasi, and S. Member, "Robust Optimal Power Management System for a Hybrid AC / DC Micro-Grid," vol. 6, no. 3, pp. 675-687, 2015.

[10] M. N. Ambia, A. Al-Durra, and S. M. Muyeen, "Centralized power control strategy for AC-DC hybrid micro-grid system using multi-converter scheme," IECON Proc. (Industrial Electron. Conf., vol. 2, no. 1, pp. 843-848, 2011.

[11] S. Transformer, X. Yu, S. Member, X. She, X. Zhou, and A. Q. Huang, "Power Management for DC Microgrid Enabled by," vol. 5, no. 2, pp. 954-965, 2014.

[12] C. Systems, "Management \& Control of Hybrid Power System," pp. 0-5, 2015.

[13] T. Ma, M. H. Cintuglu, S. Members, and O. Mohammed, "Control of Hybrid AC / DC Microgrid Involving Energy Storage, Renewable Energy and Pulsed Loads," pp. 1-8, 2015.

[14] F. R. Salmasi and M. Hosseinzadeh, "Power management of an isolated hybrid AC/DC micro-grid with fuzzy control of battery banks," IET Renew. Power Gener., vol. 9, no. 5, pp. 484-493, 2015.

[15] A. H. Kasem Alaboudy, A. A. Daoud, S. S. Desouky, and A. A. Salem, "Converter controls and flicker study of PMSGbased grid connected wind turbines," Ain Shams Eng. J., vol. 4, no. 1, pp. 75-91, 2013.

[16] Y. Errami, M. Ouassaid, and M. Maaroufi, "Control of a PMSG based wind energy generation system for power maximization and grid fault conditions," Energy Procedia, vol. 42, pp. 220-229, 2013. 
[17] M. G. Villalva, J. R. Gazoli, and E. R. Filho, "Comprehensive Approach to Modeling and Simulation of Photovoltaic Arrays," IEEE Trans. Power Electron., vol. 24, no. 5, pp. 1198-1208, 2009.

[18] Y. H. Liu, Z. Z. Yang, S. C. Wang, and J. W. Huang, "A novel analog MPPT technique for low power photovoltaic systems," IEEE Reg. 10 Annu. Int. Conf. Proceedings/TENCON, pp. 833-837, 2011.

[19] N. Huang, "Simulation of Power Control of a Wind Turbine Permanent Magnet Synchronous Generator System," pp. 197, 2013.

[20] G. J. Priya, "Modelling and Performance Analysis of Grid Connected PMSG Based Wind Turbine," Ijareeie, vol. 3, no. 2, pp. 155-165, 2014.

[21] K. Sayed, A. M. Kassem, I. Aboelhassan, A. M. Aly and A. G. Abo-Khalil, "Energy Management and Control Strategy of DC Microgrid Including Multiple Energy Storage Systems," 201921 st International Middle East Power Systems Conference (MEPCON), 2019, pp. 736-741, doi: 10.1109/MEPCON47431.2019.9008076.

[22] H. A. Gabbar and K. Sayed, "Smart distribution system Volt/VAR control using the intelligence of smart transformer," 2016 IEEE Smart Energy Grid Engineering (SEGE), 2016, pp. 52-56, doi: 10.1109/SEGE.2016.7589499.

[23] Ahmed G. Abo-Khalil and Khairy Sayed, "Wind Turbine Simulation and Control Using Squirrel-Cage Induction Generator for DFIG Wind Energy Conversion Systems", Sohag Engineering Journal (SEJ), Vol. 1, No. 1, March 2021.

[24] Khairy Sayed and Ahmed M. Kassem, "Sensorless Vector Controlled Three-Phase PWM Inverter-Fed Induction Motor Drive System with Auto-Tuning Estimation of Machine Parameter Approach", Sohag Engineering Journal (SEJ), Vol. 1, No. 1, March 2021.

[25] Almutairi, A.; Abo-Khalil, A.G.; Sayed, K.; Albagami, N. MPPT for a PV Grid-Connected System to Improve Efficiency under Partial Shading Conditions. Sustainability 2020, 12, 10310. https://doi.org/10.3390/su122410310.

[26] Sayed, K.; Abo-Khalil, A.G.; S. Alghamdi, A. Optimum Resilient Operation and Control DC Microgrid Based Electric Vehicles Charging Station Powered by Renewable Energy Sources. Energies 2019, 12, 4240. https://doi.org/10.3390/en12224240.

[27] A. Almutairi, K Sayed, N Albagami, AG Abo-Khalil, H Saleeb, "Multi-Port PWM DC-DC Power Converter for Renewable Energy Applications", Energies 14 (12), 3490.

[28] Jose P. Therattil; Jenson Jose; Praveen Raveendran Nair Prasannakumari; Ahmed G. Abo-khalil; Ali S. Alghamdi; Bindu Gopakumar Rajalekshmi; Khairy Sayed, "Hybrid control of a multi-area multi-machine power system with FACTS devices using non-linear modelling", Volume 14, Issue 10, 22 May 2020, p. 1993 - 2003.

[29] Abo-Khalil, A.G.; Alyami, S.; Sayed, K.; Alhejji, A. Dynamic Modeling of Wind Turbines Based on Estimated Wind Speed under Turbulent Conditions. Energies 2019, 12, 1907. https://doi.org/10.3390/en12101907.

[30] Sayed, K., Abo-Khalil, A.G., Eltamaly, A.M., " Wind Power Plants Control Systems Based on SCADA System",Book Chapter, Green Energy and Technology, 2021, pp. 109-151.

[31] K. Sayed, HA Gabbar, "SCADA and smart energy grid control automation", book chapter, Smart Energy Grid Engineering, 481-5142016,

[32] K. Sayed, M. Abdel-Salam, M. Ahmed, A. Ahmed, "Modeling and simulation of PV arrays", ASME International Mechanical Engineering Congress and Exposition, IMECE2010-38969, pp:1-8, Vancouver, British Columbia, Canada, November 12-18, 2010.

[33] Hedra Saleeb, Khairy Sayed, Ahmed Kassem, Ramadan Mostafa, Control and analysis of bidirectional interleaved hybrid converter with coupled inductors for electric vehicle applications", Electrical Engineering, pp. 1-28, 2019.

[34] Khairy Sayed, Farid Naguib Abdelbar, Emad Elzohri, Allam Ahmed, "Monitoring and Rationalizing Energy Consumption of Home Electric Appliances", International Journal of Innovative Research in Electrical, Electronics, Instrumentation and Control Engineering, Vol. 8, Issue 11, November 2020, DOI 10.17148/IJIREEICE.2020.81101J.

[35] Sayed, K.; Kassem, A.; Saleeb, H.; Alghamdi, A.S.; Abo-Khalil, A.G. Energy-Saving of Battery Electric Vehicle Powertrain and Efficiency Improvement during Different Standard Driving Cycles. Sustainability 2020, 12, 10466. https://doi.org/10.3390/su122410466.

[36] Sayed, K.; Ali, Z.M.; Aldhaifallah, M. Phase-Shift PWM-Controlled DC-DC Converter with Secondary-Side Current Doubler Rectifier for On-Board Charger Application. Energies 2020, 13, 2298. https://doi.org/10.3390/en13092298.

[37] Eltamaly, A.M.; Al-Saud, M.; Sayed, K.; Abo-Khalil, A.G. Sensorless Active and Reactive Control for DFIG Wind Turbines Using Opposition-Based Learning Technique. Sustainability 2020, 12, 3583. https://doi.org/10.3390/su12093583.

[38] Sayed, K.; Gronfula, M.G.; Ziedan, H.A. Novel Soft-Switching Integrated Boost DC-DC Converter for PV Power System. Energies 2020, 13, 749. https://doi.org/10.3390/en13030749.

[39] Abo-Khalil, A.G.; Alghamdi, A.S.; Eltamaly, A.M.; Al-Saud, M.S.; R. P., P.; Sayed, K.; Bindu, G.R.; Tlili, I. Design of State Feedback Current Controller for Fast Synchronization of DFIG in Wind Power Generation Systems. Energies 2019, 12, 2427. https://doi.org/10.3390/en12122427. 